Viso - Cadernos de estética aplicada Revista eletrônica de estética

ISSN 1981-4062

$N^{0} 14$, jul-dez/2013

http://www.revistaviso.com.br/

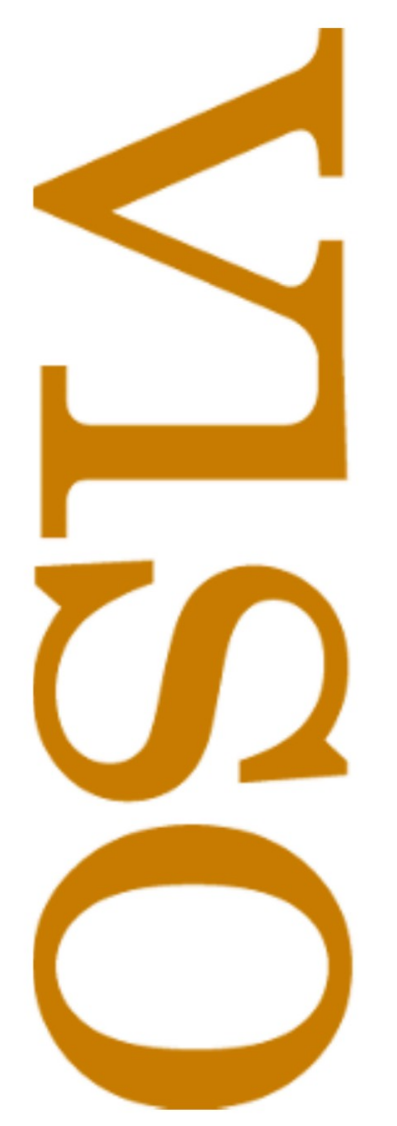

\title{
A experiência musical: Contribuições para um estudo com Kant e Peter Sloterdijk
} Ana Monique Moura 


\section{RESUMO}

A experiência musical: Contribuições para um estudo com Kant e Peter Sloterdijk

Este trabalho procura explicar o conceito de musicalidade a partir das observações de Peter Sloterdijk sobre as ressonâncias da Revolução Copernicana na filosofia de Kant. Por fim, apresentamos resultados teóricos sobre as relações dialéticas entre a filosofia da música de Kant e Sloterdijk e sua contribuição para entender aspectos sobre a experiência estética com a música na pós-modernidade.

Palavras-chave: som - música - ontologia - tonalidade

\section{ABSTRACT}

The musical experience: Contributions to a study with Kant and Peter Sloterdjk

This paper seeks to explain the concept of musicality from observations of Peter Sloterdijk on the resonances of the Copernican Revolution in Kant's philosophy. Finally, we present theoretical studies about the dialectical relationship between the music philosophy of Kant and Sloterdijk and its contribution to understanding aspects of the aesthetic experience with music in postmodernity.

Keywords: sound - music - ontology - tonality 


\section{MOURA, A. M. "A experiência musical: Contribuições para um estudo com Kant e Peter Sloterdijk". In: Viso: Cadernos de estética aplicada, v. VII, n. 14 (jul- dez/2013), pp. 28-39.}

DOI: $10.22409 / 1981-4062 / v 14 i / 156$

Aprovado: 29.04.2014. Publicado: 15.07.2014.

(C) 2014 Ana Monique Moura. Esse documento é distribuído nos termos da licença Creative Commons Atribuição-NãoComercial 4.0 Internacional (CC-BY-NC), que permite, exceto para fins comerciais, copiar e redistribuir o material em qualquer formato ou meio, bem como remixá-lo, transformá-lo ou criar a partir dele, desde que seja dado o devido crédito e indicada a licença sob a qual ele foi originalmente publicado.

Licença: http://creativecommons.org/licenses/by-nc/4.0/deed.pt_BR

Accepted: 29.04.2014. Published: 15.07.2014.

(C) 2014 Ana Monique Moura. This document is distributed under the terms of a Creative Commons Attribution-NonCommercial 4.0 International license (CC-BY-NC) which allows, except for commercial purposes, to copy and redistribute the material in any medium or format and to remix, transform, and build upon the material, provided the original work is properly cited and states its license.

License: http://creativecommons.org/licenses/by-nc/4.0/ 
A ação musical é descontínua; é nossa ressonância sentimental que lhe confere unidade. A emoção musical é assim uma tentativa, nunca plenamente completada, de realizar uma síntese temporal , pois a causalidade musical é sempre adiada, sempre sistematicamente adiada. Ela não age gradualmente.

Gaston Bachelard

La dialectique de la durée, 1950 .

soava, vibrava prodigiosamente - era música! Eu já não experimentara em outro tempo este mesmo horror, que àquela época era uma delícia?

Herman Hesse

Der Steppenwolf, 1927

Fala-se com frequência no sublime [Erhaben] abordado na Crítica da faculdade do juízo [Kritik der Urteilskraft, 1790]' de Kant, o que, no geral, tem deixado à margem uma referência ao sublime na obra pré-crítica do filósofo. Neste sentido, não por mero didatismo, mas para evitar sempre possíveis equívocos, parece devido insistir que o sublime, para Kant, se não descartamos obras anteriores à $K U$, não tem uma identidade única, pois assume três expressões distintas em Observações sobre o sentimento do belo e do sublime [Beobachtungen über das Gefühl des Schonen und Erhabenen, 1764]. O sublime, nesta obra pré-crítica, é classificado como terrificante, nobre ou magnífico. ${ }^{2}$ Estes três tipos não são inteiramente abordados na Crítica da faculdade do juízo pois ali se aborda com frequência quase imperiosa o sublime tão só concebido como o sublime magnífico, mas não segundo seu caráter de nobreza, nem segundo seu caráter de comoção [Rührung], que é o sublime terrificante ou terrível. ${ }^{3}$ Decerto que o sublime nobre e o terrível deveriam ocupar um lugar na abordagem a fim de vislumbrarmos uma globalidade do tema do sublime na obra de Kant. ${ }^{4}$

Para Kant, o sublime magnífico é aquele que demanda uma relação final com o belo, e por isso mesmo, não deve ser com ele confundido, mas apenas relacionado. Neste aspecto, os demais tipos de sublimidade, por assim dizer, mantêm uma relação outra com o que se entende por belo na estética de Kant, a saber, aquilo que apraz sem gerar um conceito epistemológico verdadeiro. Segue-se também que, se o sentimento sublime não é magnífico, a razão prontamente moral aí não se revela e, numa experiência de conhecimento, a razão pura fica isolada ao reconhecer nos seus limites uma conturbação violenta. ${ }^{5}$ Neste aspecto, a magnitude do sublime se liga tanto com o belo quanto com o moral.

Kant, dentro desse percurso, menciona que "uma longa duração é sublime" ${ }^{\circ}$, e também assume, posteriormente na $K U$, que o sublime pode ser tanto dinâmico [§28], como matemático [§25]. Isto vale, amplamente, para todos os três tipos de manifestação do 
sublime. E diríamos que o sublime possui algo de analogamente musical, na medida em que se faz como duração em seu aspecto tanto qualitativo como matemático. Em outros termos, o sentido do sublime como longa duração e exprimível, dinâmica e matematicamente, nos fornece, inicialmente, uma ponte para o anexarmos ao tema da música, pois que, assim como o sublime, a música também se faz duração e abriga a matemática e a dinâmica como categorias de expressão.

Mas antes, recuemos: outro aspecto que se deve destrinchar em detrimento de uma interpretação sempre muito possível, contudo equivocada, da abordagem kantiana sobre o sublime, é o tema do belo presente na sublimidade. Devemos evitar a possibilidade de uma separação entre sublime e belo tão só segundo o argumento de Kant de que o belo é aquilo que se liga a um prazer positivo ligado à harmonia das formas e o sublime aquilo que se liga ao prazer negativo ligado à desarmonia das formas. ${ }^{7}$ Estas definições não podem sustentar uma conclusão basilar, pois há interinamente uma relação entre o sublime e o belo, se falamos na sublimidade discutida na $K U .{ }^{8}$ Neste caso, a distinção realizada por Kant se refere aos tipos de experiências estéticas e não a uma segregação fixa entre elas. Há como nos referirmos a uma sublimidade contra a beleza, mas também é possível falarmos em uma beleza aliada à sublimidade. Isto marca como a distinção das várias expressões do sublime abordadas por Kant pode elucidar o problema estético da relação ou não relação entre o belo e o sublime, com a finalidade de salvaguardar nossa abordagem.

A matematicidade do sublime corresponde, em última instância, ao lugar da razão pura na experiência estética e a dinamicidade do sublime corresponde ao lugar da razão prática. No primeiro, a razão guarda na sua capacidade organizadora e ao mesmo tempo se revela no indivíduo como potencialmente reconhecedora de sua grandeza de ideários. ${ }^{9}$ Aqui a razão conduz a faculdade de imaginação [Einbildungskraft], outrora resignada, a levar adiante ideias racionais e, no segundo, a razão guarda o ideal da harmonia, neste caso, do belo como símbolo do bem moral.

No caso da dinamicidade do sublime, ela tem, no uso da razão, a capacidade de trazer o sentimento de contemplação do belo. O prazer no contemplado é o belo, o prazer negativo é o sublime, que é capaz, por outro lado, de abrigar um ideal de belo através da razão, quando invocada. Neste sentido, se o sublime se realiza, para Kant, isto quer dizer que, ali, em sua fase última, a experiência plena com o sublime evocou uma razão pura prática, porque a razão passou a presidir em lugar de uma imaginação ilimitada e aterradora e a exigir também a harmonia em lugar da desarmonia das faculdades subjetivas.

A exigência do sublime magnífico, para além da exigência do sublime nobre ou terrificante, que procura no que contempla a admiração, comunga com um dos preceitos da Aufklärung: a experiência moral da razão. ${ }^{10}$ Portanto, falar em Aufkläung inclui também, embora pouco referida, uma invocação da $K U$. No significado da liberdade 
intelectual do indivíduo, a Aufklärung procura exigir em suma o uso público da razão. Isto se liga, básica e inevitavelmente, com o tema da moral. A estética de Kant se relaciona com os preceitos da Aufklärung na medida em que aprova a comunicabilidade da experiência em uma cultura estética que vise a moral como sua honrável adição. Tudo isto está interligado, insiste-se, ao tema de uma razão autônoma, própria da Aufklärung. Contudo, o tema do sublime na estética vem, ainda assim, para desafiar a intenção precisa da possibilidade do potencial moral e autônomo da razão. E isto não se dá tão somente a partir da terceira crítica, uma vez que, em 1781, na Kritik der reinen Vernunft, ${ }^{11}$ (Crítica da Razão Pura) Kant já antecipara o tema da conturbação da razão, ainda que em via de assunto epistemológico, quando afirmava: "a razão humana, num determinado domínio dos seus conhecimentos, possui o singular destino de se ver atormentada". ${ }^{12}$

No caso da matematicidade do sublime, há uma evocação à certeza de uma razão pura capaz de se impor diante da grandeza daquilo que manifesta a sublimidade. Para Kant, ao sublime "é necessário ser sempre grande". ${ }^{13}$ A razão pura aqui não abordará o entendimento com vista ao conhecimento ou formação do conceito quantitativo da obra ou da natureza, mas servirá como segurança ao sujeito de que aquilo que ele não pode mensurar é parte de um reconhecimento dos limites da própria razão. ${ }^{14}$ Neste sentido, após a conturbação diante da grandeza, o sujeito se tranquiliza ao reconhecer seus limites e assumir para si a posse possível de uma razão pura. Em Kant, a imaginação é impedida pela razão de se arvorar para além do que a própria razão permite. Sobre isso Kant afirma que a "faculdade de imaginação e razão produzem aqui através do seu conflito, a conformidade a fins subjetiva das faculdades de ânimo; ou seja, um sentimento de que nós possuímos uma razão pura...." ${ }^{15} \mathrm{O}$ espírito subjetivo é animado para esta espécie de certeza.

É nesta medida em que, embora o sublime aqui não seja estético por não ser puro como o belo para Kant, a razão pura pode entrar numa experiência sublime sem retirar a grande identidade de um sentimento estético, que é ligar-se à apreciação da natureza ou da obra, sem a especulação ou a constituição de conceitos. ${ }^{16}$ Antes, a razão adentra neste terreno para reconhecer sua incapacidade diante das finalidades epistemológicas. Em relação à dinâmica, ou seja, à qualidade, do sublime, há aqui um papel inegavelmente moral no pensamento de Kant: a dissonância da independência que o belo tem com a razão, porque o belo já possui sua própria harmonia formal. No caso do sublime, por ser conturbador, evoca uma razão capaz de idealizar o belo, ou seja, a harmonia das faculdades e alimenta simultaneamente um sentimento moral no sujeito que o engrandeça e o iguale perante a natureza. Neste aspecto, o sublime é vivenciado por uma comoção [Gefühl] que, dizemos com Kant, "é por vezes acompanhado de certo assombro ou também de melancolia, em alguns casos apenas de uma calma admiração e, noutros, de uma beleza que atinge uma dimensão sublime". ${ }^{17} \mathrm{O}$ belo e o sublime podem ser comungados a depender da forma da experiência a que o espírito se lança com a sublimidade. 
Voltemos para a nossa referência à música. Kant denomina a música, no $\S 51$ da $K U$, como "belo jogo das sensações" [schönes Spiel der Empfindungen]. Ele pensa o belo como fruto do livre jogo entre entendimento [Verstand] e imaginação [Einbildungskraft]. Então, como algo pode ser belo partindo tão só de um jogo de sensações e não daquele jogo? Será, perguntariam e perguntam, que Kant relegou a música a uma arte menos estética do que as outras? Embora realizada esta pergunta, o importante aqui não é tentar capturar qual a melhor arte segundo Kant, mas procurar investigar o modo estrutural como, no caso da nossa pesquisa, a música se revela, seja menos importante ou não, na estética global de Kant.

As sensações [die Empfindungen] podem compor tanto o meramente agradável como o prontamente estético, e falar em "belo jogo das sensações" nos traz um problema relacionado a essa ambiguidade. Kant parece relegar a música a algo que a diferencia quase que completamente do nível das outras artes. Não se trata de um belo jogo das faculdades, mas de um belo jogo das sensações. Neste caso, há uma possibilidade de se falar aqui em uma espécie de música agradável que alça uma quase música bela e estética, contudo não o faz plenamente. É como se a música provocasse um sentimento crítico e estético de maneira muito superficial, ou, quando considerada bela, provocasse também uma sensação meramente agradável e não prontamente um sentimento estético. ${ }^{18} \mathrm{O}$ belo aqui estaria posto a uma harmonia das sensações próprias do agradável [angenehm] entretenimento musical. Kant reconhece a problemática de se definir o lugar da música em relação à nossa apreensão. Fica difícil definir quando se trata de uma apreensão mediante um juízo estético ou uma sensação agradável. Reiteremos que Kant considera possível, na medida em que menciona "belo jogo das sensações", a possibilidade de que a música se apresente como arte bela, mesmo, como ele diz, "em parte" sendo arte agradável. ${ }^{19}$ Kant quer deixar pensável, portanto não concluidamente pensada, a categoria da música enquanto algo que possa agradar sem ser, inteiramente, algo de mero entretenimento, embora não tão radicalmente como ele pensa, uma arte prontamente reflexiva.

Sloterdijk vem nos falar de um ouvido ontológico como órgão de uma subjetividade crítica (já reivindicada pela filosofia transcendental de Kant). A musicalidade da filosofia está imbuída de fragmentos e procedimentos atonais enquanto expressividade copernicana e a tonalidade aparece como o ponto ptolomaico. Aqui "a ordem perturbada se restaura consequentemente pela amputação do sujeito falsário, ou seja, pela reintegração da desarmonia numa relação objetiva, pela reintrodução numa tonalidade cósmica”. ${ }^{20}$ Isso marca a expressão do prazer e desprazer como marcas de uma experiência estética, já pensada em Kant.

Trata-se, também, de realizar algo próximo da leitura pitagórica do universo, segundo a qual ele se exprime em uma partitura infinita. A musicalidade abordada por Slotertijk 
chega a suprimir a própria matematicidade ou as relações puras pitagóricas. O âmbito musical aqui assume o problema da experiência estética na pós-modernidade e não se limita ao aspecto cosmocêntrico da harmonia e da ordem, embora isto seja sempre manifesto em meio ao caos dos fragmentos sonoros. "Se a matemática desfruta em todo momento duma proximidade intelectual com a música, quando o produto finalizado se oferece à experiência sensível, a matemática desaparece completamente". ${ }^{21}$ Contudo, essa harmonia clássica não é o que se revela como peremptória. A atonalidade e a dissonância ainda são os fatores que marcam nossa época. Valeria acrescentar, a partir das chaves de Soterdijk, que o ideal de harmonia pitagórica na Antiguidade era uma forma de manifesto. Neste sentido, se havia uma exigência de relações puras e harmonia, o que havia de fato, anterior ao que se exigia, era a crise da harmonia. No caso de nossa época, para Sloterdijk, o que temos é um excesso de harmonias, uma saturação de formas historicamente organizadas como formas ditas puras da música, contra as quais o processo criativo musical segue, por exemplo, com o atonalismo. Neste caso, não é a harmonia, na medida em que é descartada, que está em crise, mas a própria dissonância, já que ela é exigida. Aqui, enquanto a experiência vivida musical traz uma supressão da matemática, o que resta é a duração da experiência estética, que é paradoxalmente um dado matemático, contudo, algo que suprime valores puros. Condição a priori indispensável da música, a matemática não parece finalmente tão indispensável quanto se podia crer, devido ao fato de que o sujeito afetado não a reconhece mais. ${ }^{22} \mathrm{~A}$ duração se liga aqui ao imprevisível, como na tese kantiana da sublimidade terrível.

Sloterdijk destina a crise da metafísica como a exigência de um ouvido neometafísico, e coloca no significado do tom da filosofia em nossos tempos o que pode ser tomado como um reforço de que não há catástrofe alguma para a filosofia. Portanto, a realização da tentativa de pensar uma ontologia, por assim dizer, musicológica, não deve trazer uma exatidão do que tenta defender e manifestar, senão exibir a investigação filosófica como uma composição musical e trazer aqui a postura nietzschiana conduzida de uma maneira mais radical, segundo o sentido de que conhecer é criar. Contudo, em Sloterdijk isso significa criar musicalmente.

Em relação à física quântica, o som corresponde a um significado mais abrangente e reinventado ${ }^{23}$, porque holístico, e é nessa perspectiva que Sloterdijk, inspirado pelo físico Berendt, vem nos dizer que o mundo é som ou, precisamente, die Welt ist Klang, frase que é título de obra do físico referido. Portanto, quando se diz que "o mundo é som" estáse dizendo ao mesmo tempo que o mundo é aquilo que você escuta. Investigar o mundo é compô-lo. E compor implica compor musicalmente. Sloterdijk inaugura aqui uma ontologia musical do ser e, para tanto exige um ouvido neometafísico.

Se assumimos que o mundo é som, assumimos, ao mesmo tempo, que o mundo não é música. A música é a tentativa de organizar o som. Se, agora, com a pós-modernidade, estamos diante de uma espécie de culto aos ruídos nas musicalidades, é porque 
estamos carecendo de "estar no mundo" prontamente, enquanto som em densidade e complexidade, para além de uma tonalidade canonicamente harmoniosa. $\mathrm{O}$ tom da filosofia consiste em estar em meio a esses sons e reconhecer que a música ontológica enquanto um todo, ou a musicalidade enquanto expressão cabal, é impossível de ser apreendida.

O aspecto do som é a duração de sua audição. Aqui entra, portanto, o jogo dialético entre o tonal e o atonal. $O$ homem dura-se nesse som e isto marca uma experiência estética histórica. O canto dos pardais hoje, e não mais o silêncio da coruja filosófica de ontem. Dizer que o mundo é som significa assumir também naquilo que não se escuta o reconhecimento do som e, ainda assim, o esforço por uma nova escuta autêntica, o que implica negar as ordens positivistas, masculinas e lógicas de percepção estética. Diante disso, diz Sloterdijk,

o indivíduo dos novos tempos precisa de novo aprender a ouvir. Seu caminho deve levar das "concepções" de mundo catastróficas, masculinas, ofensivas, rapinas, de volta ao acolhimento auditivo e à unissonância harmoniosa do regime suave dos sons. O ouvido feminiliza o intelecto. ${ }^{24}$

Portanto, o processo de apreensão está invertido. Não é mais a esfinge que tem algo a dizer, que precisa ser decifrada. Agora a subjetividade se impõe diante da esfinge e the insufla um significado: "Não deveríamos mais fingir desafiar a esfinge enigmática, duelar perigosamente com a alteridade radical." ${ }^{25}$ Daqui se segue que "o próprio mundo é o evidente, o audível, o conhecível, o revelado, o 'descoberto'. Esses enunciados uma vez pronunciados equivalem à morte da investigação pela investigação". ${ }^{26} \mathrm{~A}$ investigação, reiteramos, passa a ser composição.

A investigação como composição traz, a contragosto do positivismo, a tese de que a o mundo é inventado. Inventar é, portanto, nas palavras de Sloterdijk, "participar da introdução do real". A experiência estética positivista procura antecipar a descoberta do mundo e da obra. E esse tem sido o problema das tentativas acadêmicas de lidar com o universo da obra de arte, em especial a música. Então, faz-se preciso que a urgência pelo conhecível se rompa, já que tudo se encontra passível de ser conhecido. Se outrora a harmonia pitagórica revelava a crise da harmonia, o recurso ao conhecível revela a crise do que se toma por conhecimento. Uma vez que o método positivista é abandonado, também se revela aí a impossibilidade da crise do conhecimento. Para Peter Sloterdijk, o que era, portanto, um sonho na filosofia transcendental kantiana, mostra-se inteiramente vivo e real aqui, no mundo pós-exclusivista, para não dizer pósmoderno. A experiência desarmônica e dissonante da razão é a grande revelação de uma abundância de harmonia. $E$ isto é muito bem expresso no cenário histórico da música, se for invocado. 
Para Kant, a tentativa de inaugurar uma observação do sublime se liga a um projeto de cultura moral no qual o sujeito sobreleva-se à sua condição de "desfragmentar-se" para assumir uma condição de unidade entre ele e a natureza. Neste aspecto, o sublime significará aqui uma expressão da totalidade, uma experiência em que o sujeito reconhece o magnífico, ou ainda, em que vê resolvido seu conflito com a natureza. Esta estabilidade de uma resolução é, por fim, um elemento que representa "certeza". Mas esta "certeza" se expressa em uma posição declaradamente, assim pretende-se, copernicana. É o voltar-se do sujeito a si próprio para enfrentar aquilo em que a natureza Ihe afeta.

Falar em copernicanismo significa falar sobre aquilo que desloca a determinação imperativa do conhecimento. E talvez a saída para este nó esteja na tese de Kant sobre o sublime terrível. Sua terribilidade consiste, por fim, que aqui a determinação alcançada na experiência do sublime magnífico não existe. O que torna o sentimento algo de sublime terrível é a capacidade de ele ser uma experiência durável. Esta duração é a marca de uma contemplação que se demora naquilo que é imprevisível. Isso revela uma contemplação terrível, como comentamos acima na primeira parte deste texto. Aqui se lança o sentimento de prazer e desprazer [Lust und Unlust], em um movimento no qual um aceita e nega o outro e, portanto, coexistem, mas esta coexistência se lança para o abismo da imaginação estética que não é socorrida por uma razão prática ou normativa. Ela está sozinha e prolonga-se neste abismo indeterminado.

Aqui, então, a experiência se revela em sua expressão de caráter mais indeterminável por excelência. $\mathrm{O}$ indeterminado marca a postura copernicana da experiência. E este copernicanismo é, ele próprio, alimentado por uma posição ptolomaica, já que o deixarse no indeterminado significa a falta de crise da determinação. Seguindo o jogo de reflexão de Sloterdijk, busca-se o indeterminado porque a presença da determinação está por demais presente. A busca pelo indeterminado revela a vitalidade da determinação.

O imprevisível se mostra prenhe do possível, por isso é imprevisível no manancial das possibilidades. Aqui o sentido de exclusivismo cai por terra e não parece, portanto, gratuito, que Sloterdijk nomeie a pós-modernidade de pós-exclusivismo. A pósmodernidade estaria, acreditamos, marcada pelo estandarte do sublime terrível. $\mathrm{Na}$ filosofia, segundo Sloterdijk, são os pardais em seu assovio que melhor simbolizam isto.

O conjunto de fatos sociais se revela como dados fragmentados, resultados desconexos, um caso, para além de visual, sonoro. ${ }^{27} \mathrm{O}$ processo de estetização na modernidade pósexclusivista não é outra coisa que a atitude de tomar o som para retirar dele música. 
O musical só existe na condição de ser pós-sonoro. A musicalização não é outra coisa que o modo de determinar e direcionar o som e dar a ele um fim numa cultura. Mas o mundo não poderia ser, inteiramente, música. "O som total seria a morte da música, seria a superação de qualquer música por uma substância que, em virtude de seu caráter sonoro, se revelaria como inferno eterno de harmonia sem sentido". ${ }^{28} \mathrm{O}$ ouvido neometafisico vem, portanto, exigir do mundo o som como apenas uma das possíveis verdades sobre ele. Aqui a imaginação estética, discutida e ao mesmo tempo evitada por Kant, sobre uma contemplação terrível, ou seja, sem recurso a uma forma pura para o significado de musicalidade, parece ser um dado presente, de valor estético e quando muito, apenas ontológico, jamais declaradamente normativo. Contudo, a forma pura e a normatividade permanecem como o grande ponto ptolomaico que subjaz neste manancial de experiências sonoras atuais, com certa insistência. É por isso, talvez, que sempre se invocará, com certa obrigação, Bach e Mozart, em tempos de Stockhausen. E ainda, nessa esteira, o belo, em meio ao sublime.

\section{* Ana Monique Moura é doutoranda em filosofia pela UFPB/UFPE/UFRN.}

${ }^{1}$ De agora em diante essa obra será abreviada como $K U$.

2 KANT, I. Observações sobre o sentimento do belo e do sublime. Tradução de Vinícius de Figueiredo. Campinas, SP: Papirus Editora, 1994, p. 22.

${ }^{3} \mathrm{KU}, \mathrm{B} 98,99, \S 27$.

${ }^{4}$ Henry Allison aborda o tema do sublime como um mero apêndice da estética kantiana na obra Kant's theory of taste. New York: Cambridge University Press, 2001.

${ }^{5}$ Cf. Op. cit., B $111 \S 29$.

${ }^{6}$ KANT, I. Observações sobre o sentimento do belo e do sublime. Op. cit., p. 23.

7 Sobre a indicação desta separação cf. GASHÉ, R. The Idea of Form. Standford: Standford University, 2003, p. 119.

${ }^{8}$ KANT, I. Observações sobre o sentimento do belo e do sublime. Op. cit. p.22.

${ }^{9} \mathrm{O}$ tema fica mais explícito em $K U$, B 87 §26.

10 ,"Zu dieser Aufklärung aber wird nichts erfordert als Freiheit; und zwar die unschädlichste unter allem, was nur Freiheit heissen mag, nämlich die: von seiner Vernunft in allem Stücken öffentlichen Gebrauch zu machen". KANT, I. Resposta à pergunta: O que é Esclarecimento? Edição Bilíngue. Tradução deGuido Antônio de Almeida. Petrópolis: Editora Vozes, 1986.

${ }^{11}$ De agora em diante, KrV.

${ }^{12} \mathrm{KrV}$ A VII.

${ }^{13}$ KANT, I. Observações sobre o sentimento do belo e do sublime. Op. cit., p. 22.

${ }^{14}$ Cf. $\left.K U, B\right) 86$ §26.

${ }^{15} \mathrm{Ibdem}, \mathrm{B} 99$ §27.

${ }^{16}$ Cf. Ibdem,B 98, 99 §27.

${ }^{17}$ Ibidem, loc. cit. 
${ }^{18}$ Sobre as diferenças entre as artes meramente agradáveis e as artes estéticas, Cf. KU $176 \S 43$.

19 Ibdem, B 212, §51.

${ }^{20}$ SLOTERDIK, P. Mobilização copernicana e desarmamento ptolomaico. Tradução de Heidrun Krieger Olinto. Rio de Janeiro: Tempo Brasileiro, 1992, p. 95.

${ }^{21}$ KERSZBERG, P. "Sur l'impossible critique d'une raison musicale". In: Kairós, n. 21, pp. 53-72, 2003, p. 66.

22 Ibidem, loc. cit.

${ }^{23}$ A física mecânica nos diz que o som é aquilo que se propaga em um limite para o ouvido humano segundo uma frequência mecânica entre $20 \mathrm{Hrz}$ e $20000 \mathrm{Hrz}$. Abaixo ou superior a isso, as ondas são infrassons ou ultrassons.

${ }^{24}$ Ibidem, p. 92.

${ }^{25}$ Ibidem, p. 102.

${ }^{26}$ Ibidem, loc. cit.

27 Material indicável para seguir a partir deste texto: FLUSSER, V. O universo das imagens técnicas.São Paulo: Anablume, 2008. Nesta obra Flusser trabalha uma ideia sobre a relação entre o visual e o sonoro. Aqui ele prenuncia "Por isso proponho, em resposta a Schopenhauer, que o universo das tecno-imagens seja considerado o mundo da música imaginativa" (p. 202).

${ }^{28}$ Ibidem, p. 108. 